\title{
Small-aperture corneal inlay in presbyopic patients with prior phakic intraocular lens implantation surgery: 3-month results
}

This article was published in the following Dove Press journal:

Clinical Ophthalmology

2I August 2013

Number of times this article has been viewed

\author{
Tukezban Huseynova' \\ Tomomi Kanamori' \\ George O Waring IV² \\ Minoru Tomita ${ }^{1,3,4}$ \\ 'Shinagawa LASIK Center, Tokyo, \\ Japan; ${ }^{2}$ Medical University of South \\ Carolina, Charleston, SC, USA; \\ ${ }^{3}$ Wenzhou Medical College, Wenzhou, \\ People's Republic of China; ${ }^{4}$ Eye Can \\ Cataract Surgery Center, Metro \\ Manila, Philippines
}

\begin{abstract}
We report a series of three case reports of KAMRA inlay implantation procedures in presbyopic patients with a history of prior phakic intraocular lens implantation surgery. Three-month results showed a two to five-line improvement for uncorrected near visual acuity. The absolute uncorrected near visual acuity change for case 1 was from J4 to J2, for case 2 was from J6 to J4, and for case 3 was from J10 to J5. No significant change of uncorrected distance visual acuity was observed in all three cases.
\end{abstract}

Keywords: phakic intraocular lens, IOL, KAMRA, intracorneal inlay

\section{Introduction}

Optical approaches to compensate for presbyopia include reading glasses, monovision, multifocal contact lenses, multifocal intraocular lenses (mIOLs), and accommodating IOLs. None of these can restore accommodation, but all are compromises that establish a fair quality of near vision at the expense of good far vision. Even a small amount of astigmatism provides some pseudoaccommodation in pseudophakic patients. ${ }^{1}$ Several methods to restore accommodation with scleral expansion near the ciliary body were designed; however, none has proven to be effective..$^{2-4}$ Corneal procedures for the compensation of presbyopia include presbyopic laser in situ keratomileusis (presby-LASIK), conductive keratoplasty, intracorneal implants (or inlays), and the INTRACOR and SUPRACOR (Technolas Perfect Vision GmbH, Munchen, Germany) procedures. We describe a case series of patients with a history of prior phakic IOL implantation surgery in whom an intracorneal inlay (KAMRA) (model ACI 7000PDT, AcuFocus Inc, Irvine, CA, USA) was implanted in the nondominant eye after creating a femtosecond laser corneal pocket. The KAMRA small-aperture intracorneal inlay is designed to increase the depth of focus in the implanted eye, based on the principle of small-aperture optics. ${ }^{5}$ The inlay restores near and intermediate visual acuity without a significant impact on distance vision. ${ }^{6-8}$

\section{Case reports}

This study conforms to the ethics codes established by the Ethical Board Committee of Japan. All patients read and signed informed consent forms, which explained the surgical procedure, possible risks, and patients' rights. This case study includes three eyes with a history of prior phakic IOL implantation surgery. The patient demographics for all three cases are presented in Table 1.
Correspondence: Minoru Tomita ITOCiA I4F, 2-7-I Yurakucho,

Chiyoda-ku, Tokyo 100-0006, Japan Tel +8I 3 522I 2207

Fax +81352218038

Email tomita@shinagawa-lasik.com 
Table I Patient demographics

\begin{tabular}{|c|c|c|c|}
\hline & \multicolumn{3}{|c|}{ Phakic IOL eyes } \\
\hline & Case I & Case 2 & Case 3 \\
\hline Age, years & 55 & 54 & 51 \\
\hline Pocket depth, $\mu \mathrm{m}$ & 230 & 200 & 200 \\
\hline \multicolumn{4}{|l|}{ Pupil size, mm } \\
\hline Photopic & 3.49 & 4.38 & 5.38 \\
\hline Mesopic & 4.14 & 5.81 & 7.09 \\
\hline \multicolumn{4}{|l|}{ UDVA } \\
\hline Preop & $20 / 20$ & $20 / 16$ & $20 / 16$ \\
\hline 3 months & $20 / 16$ & $20 / 20$ & $20 / 20$ \\
\hline \multicolumn{4}{|l|}{ CDVA } \\
\hline Preop & $20 / 16$ & $20 / 16$ & $20 / 16$ \\
\hline 3 months & $20 / 16$ & $20 / 16$ & $20 / 16$ \\
\hline \multicolumn{4}{|l|}{ UNVA } \\
\hline Preop & J4 & J6 & J10 \\
\hline 3 months & $\mathrm{j} 2$ & $\mathrm{j} 4$ & $\mathrm{j} 5$ \\
\hline \multicolumn{4}{|l|}{ CNVA } \\
\hline Preop & 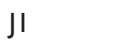 & اנ & ו I \\
\hline $3 M$ & J & 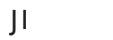 & Jl \\
\hline \multicolumn{4}{|l|}{ MRSE, D } \\
\hline Preop & -0.25 & -0.50 & 0.00 \\
\hline 3 months & -1.00 & -0.38 & -0.50 \\
\hline
\end{tabular}

Abbreviations: CDVA, corrected distance visual acuity; CNVA, corrected near visual acuity; D, diopter; IOL, intraocular lens; MRSE, manifest refraction spherical equivalent; UDVA, uncorrected distance visual acuity; UNVA, uncorrected near visual acuity.

The aim of the present study was to show the efficacy of the KAMRA small-aperture intracorneal inlay in presbyopic patients with prior refractive surgeries, which was one of the exclusion factors in previous reports. ${ }^{5,8-10}$

The preoperative and postoperative assessment of patients and surgical techniques is already described in our previous study. ${ }^{9}$ Patient satisfaction after surgery was estimated from the patients' satisfaction questionnaires, as was done previously. ${ }^{9}$

\section{Case I}

A 55-year-old woman had presbyopia correction with inlay implantation in her left eye. Her preoperative visual acuity was evaluated using a Snellen chart for distance and LogMAR for near vision (which was converted to a Jaeger chart thereafter). Preoperative spherical equivalent (SE) was -0.25 diopter (D); uncorrected distance visual acuity (UDVA) and corrected distance visual acuity (CDVA) were 20/20 and 20/16, respectively; and uncorrected near visual acuity (UNVA) and corrected near visual acuity (CNVA) were J4 and $\mathrm{J} 1$, respectively. Corneal thickness was $603 \mu \mathrm{m}$. The patient underwent a comprehensive preoperative examination. ${ }^{9}$ During surgery, the corneal pocket creation was done for the KAMRA inlay implantation with a Crystal Line Femto LDV (Ziemer Ophthalmic Systems AG, Port, Switzerland).
The KAMRA inlay implantation was done with a $230 \mu \mathrm{m}$ pocket depth, not $200 \mu \mathrm{m}$ as is usual, due to the presence of $603 \mu \mathrm{m}$ central corneal thickness. The inlay was carefully placed in the pocket over the estimated line of sight based on the midpoint of the first Purkinje image and the pupil center with coaxial patient fixation. ${ }^{9}$ Three-month results showed an improvement in UNVA to J2, with even better outcomes for UDVA, which improved to 20/16 (Table 1). SE was -1.0 D. CDVA and CNVA remained stable during the follow-up period. The patient did not report needing reading glasses in any light conditions.

\section{Case 2}

A 54-year-old woman with a history of a LASIK procedure that was done soon after her prior phakic IOL implantation surgery complained about her near vision. The patient underwent a rigorous ophthalmic examination. ${ }^{9}$ UDVA and CDVA were both 20/16; UNVA and CNVA were J6 and J1, respectively. SE was $-0.5 \mathrm{D}$ and pachymetry was $487 \mu \mathrm{m}$. During surgery, the corneal pocket formation was done for her KAMRA inlay implantation with a Crystal Line Femto LDV (Ziemer Ophthalmic Systems AG). The KAMRA inlay was implanted using a pocket depth of $200 \mu \mathrm{m}$. The inlay was placed in the pocket the same way as has already been described. ${ }^{9}$ Three-month results showed an improvement in UNVA to J4 with minimal change in UDVA, which was 20/20. SE was -0.38 D. CDVA and CNVA remained stable during the follow-up period. Regarding patient satisfaction, the patient complained of a slight worsening of her near vision at night.

\section{Case 3}

A 51-year-old woman was a candidate for presbyopia treatment by KAMRA inlay implantation surgery. One month

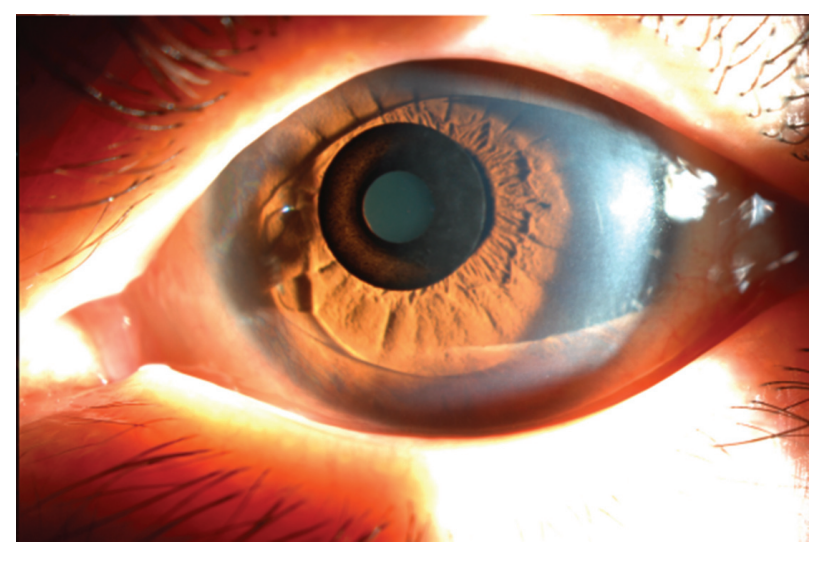

Figure I The phakic intraocular lens eye with implanted KAMRA inlay. 
before inlay surgery, the patient underwent a LASIK procedure in order to correct the refractive error after her first phakic IOL implantation procedure. The patient underwent a comprehensive preoperative examination the same as the other patients. SE just before inlay implantation surgery was 0.00 D. UDVA and CDVA were both 20/16. UNVA and CNVA were J10 and J1, respectively. Corneal thickness was $494 \mu \mathrm{m}$. The KAMRA inlay was implanted the same way as with the case 2 patient at a depth of $200 \mu \mathrm{m}$. There was an improvement in UNVA at the 3-month follow up, from J10 to J5. A minimal change in UDVA was observed, but it was still 20/20 postoperatively. SE was -0.5 D. CDVA and CNVA remained stable. At the 3-month follow-up the patient mentioned needing reading glasses only occasionally.

\section{Discussion}

The KAMRA corneal inlay was used in this study. The inlay's polyvinylidene difluoride material incorporates nanoparticles of carbon to make it opaque. ${ }^{5}$ This permeable material has a light transmission rate of 5\%. The inlay has a pseudorandom microperforation pattern consisting of 8,400 holes ranging in size from $5 \mu \mathrm{m}$ to $11 \mu \mathrm{m}$ in diameter, to allow water and nutrition flow. The inlay is $5 \mu \mathrm{m}$ thin and has a $3.8 \mathrm{~mm}$ total diameter and a $1.6 \mathrm{~mm}$ diameter central aperture. There is no refractive power in the central aperture. ${ }^{9}$ The KAMRA inlay can be implanted under a flap or into an intrastromal pocket, both created by a femtosecond laser. All three patients of our study had corneal pocket formation during the inlay implantation.

In the postphakic eye of case 1, the main point to mention is that the KAMRA inlay implantation was with a $230 \mu \mathrm{m}$ depth pocket due to $603 \mu \mathrm{m}$ central corneal thickness appearing. The UNVA improved by two lines at 3 months postoperatively in this patient. No need for reading glasses was reported from this patient. In all presented cases, the corneal inlay was implanted as per the normal post-LASIK procedure using a pocket. We saw near vision improvement in all patients with postphakic eyes. Only one patient (case 2) reported some worsening of her near vision at night. The reason for this may be the decreasing of the depth of focus with a larger pupil diameter.

Figure 2 presents the UNVA change during the entire follow-up period for all three cases.

Thus, based on our results, with improved near visual acuity, minimum impact on UDVA, and the appearance of clear corneas, with no opacities or changes in epitheliums, we may consider that KAMRA inlay surgery in postphakic

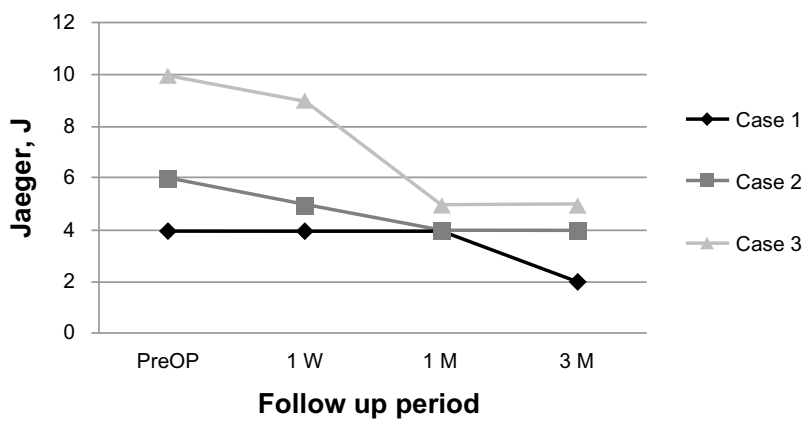

Figure 2 Changes in uncorrected near visual acuity in the eyes with the inlay during 3-month follow-up.

Abbreviations: PreOP, preoperative; W, week; M, month.

IOL patients appears to be safe. No changes in topography images were observed.

Additionally, it should be noted that there are other options for presbyopia corrections, such as intrastromal femtosecond laser correction and mIOL. But we consider, based on the reported study, ${ }^{11}$ that intrastromal femtosecond laser correction has more impact on UDVA than does KAMRA inlay. mIOL implantation might be another option for these patients, but as the patients of our study did not have any cataract formation, and knowing that cataract surgeries are not as safely reversible as KAMRA inlay surgeries, the patients of our study were not good candidates for mIOL surgery.

\section{Conclusion}

In summary, our case report study results suggest that the implantation of a KAMRA corneal inlay may improve monocular near visual acuity in presbyopic patients with a history of a prior phakic IOL implantation surgery, based on our short-term follow-up.

\section{Disclosure}

Tukezban Huseynova and Tomomi Kanamori do not have any proprietary interest in any material or method mentioned in this paper. Minoru Tomita and George O Waring IV are consultants for Acufocus.

\section{References}

1. Huber C. Planned myopic astigmatism as a substitute for accommodation in pseudophakia. J Am Intraocular Implant Soc. 1981;7(3): 244-249.

2. Schachar RA. Theoretical basis for the scleral expansion band procedure for surgical reversal of presbyopia [SRP]. Compr Ther. 2001;27(1): 39-46.

3. Qazi MA, Pepose JS, Shuster JJ. Implantation of scleral expansion band segments for the treatment of presbyopia. Am J Ophthalmol. 2002;134(6):808-815.

4. Mathews S. Scleral expansion surgery does not restore accommodation in human presbyopia. Ophthalmology. 1999;106(5):873-877. 
5. Yilmaz OF, Bayraktar S, Agca A, Yilmaz B, McDonald MB, van de Pol C. Intracorneal inlay for the surgical correction of presbyopia. J Cataract Refract Surg. 2008;34(11):1921-1927.

6. Waring GO 4th. Correction of presbyopia with a small aperture corneal inlay. J Refract Surg. 2011;27(11):842-845.

7. Seyeddain O, Hohensinn M, Riha W, et al. Small-aperture corneal inlay for the correction of presbyopia: 3-year follow-up. J Cataract Refract Surg. 2012;38(1):35-45.

8. Dexl AK, Seyeddain O, Riha W, Hohensinn M, Hitzl W, Grabner G. Reading performance after implantation of a small-aperture corneal inlay for the surgical correction of presbyopia: two-year follow-up. J Cataract Refract Surg. 2011;37(3):525-531.
9. Tomita M, Kanamori T, Waring GO 4th, et al. Simultaneous corneal inlay implantation and laser in situ keratomileusis for presbyopia in patients with hyperopia, myopia, or emmetropia: six-month results. $J$ Cataract Refract Surg. 2012;38(3):495-506.

10. Dexl AK, Seyeddain O, Riha W, et al. Reading performance after implantation of a modified corneal inlay design for the surgical correction of presbyopia: 1-year follow-up. Am J Ophthalmol. 2012;153(5): 994-1001.

11. Menassa N, Fitting A, Auffarth GU, Holzer MP. Visual outcomes and corneal changes after intrastromal femtosecond laser correction of presbyopia. J Cataract and Refractive Surg. 2012;38(5):765-773.
Clinical Ophthalmology

\section{Publish your work in this journal}

Clinical Ophthalmology is an international, peer-reviewed journal covering all subspecialties within ophthalmology. Key topics include: Optometry; Visual science; Pharmacology and drug therapy in eye diseases; Basic Sciences; Primary and Secondary eye care; Patient Safety and Quality of Care Improvements. This journal is indexed on

\section{Dovepress}

PubMed Central and CAS, and is the official journal of The Society of Clinical Ophthalmology (SCO). The manuscript management system is completely online and includes a very quick and fair peer-review system, which is all easy to use. Visit http://www.dovepress.com/ testimonials.php to read real quotes from published authors. 